\title{
A Performance Comparison between GIS-based and Neuron Network Methods for Flood Susceptibility Assessment in Ayutthaya Province
}

\author{
Thanat Vajeethaveesin ${ }^{1}$, Teerapong Panboonyuen², Siam Lawawironjwong ${ }^{3}$, \\ Panu Srestasathiern ${ }^{3}$, Saichon Jaiyen ${ }^{4}$ and Kulsawasd Jitkajornwanich,"* \\ ${ }^{1}$ Data Science and Computational Intelligence Laboratory, Department of Computer Science, \\ School of Science, King Mongkut's Institute of Technology Ladkrabang, Bangkok 10520, Thailand \\ ${ }^{2}$ Department of Computer Engineering, Faculty of Engineering, Chulalongkorn University, \\ Bangkok 10330, Thailand \\ ${ }^{3}$ Geo-Informatics and Space Technology Development Agency (Public Organization), \\ Bangkok 10210, Thailand \\ ${ }^{4}$ School of Information Technology, King Mongkut's University of Technology Thonburi, \\ Bangkok 10140, Thailand
}

("Corresponding author's e-mail: kulsawasd.ji@kmitl.ac.th)

Received: 25 August 2020, Revised: 25 May 2021, Accepted: 25 June 2021

\begin{abstract}
Flooding has been a long withstanding issue in Thailand. Due to its geographical setup, mitigation and management of floods are challenging and hard to execute. One of the tools used in managing the events is "flood susceptibility mapping," in which an incident probability as well as a rescue path is estimated and planned. To create one, the traditional GIS method called FRAM (flood risk assessment model), combined with AHP (analytical hierarchy process), is used and implemented on ArcGIS software. In this method, we first created a comparison table to compute weights for each of the selected factors. Then the computed weights were used in the FRAM model in ArcGIS to create a flood susceptibility map for each region. Each region was then classified as very high, high, medium, low, and very low risk. On the other hand, in computer science, machine learning and AI are prevalent and being adopted to various domains, promising the effectiveness of the method, potentially beat the forementioned traditional method. Therefore, ANN (artificial neural network) is adopted in this work to create the flood susceptibility map. The ANN technique is developed by using causal factors. The ANN classifies areas as either flood areas or flood-free areas. The 2 methods from different disciplines (GIS and Computer Science) are applied and described in this paper with the intention to prove whether the machine learning is really efficient and can outperform the traditional GIS approach. Data on Thailand's Ayutthaya Province is used in this work as a case study - in order to assess flood prone areas and compared for performance evaluation. Both of which use the 6 selected factors according to the literature: (i) flow accumulation, (ii) elevation, (iii) land use, (iv) rainfall intensity, (v) slope and (vi) soil types. The results from the 2 methods were verified with historical flood data and compared. The results showed that ANN (obtained via sensitivity analysis) outperformed the FRAM with precision of $79.90 \%$, recall of $79.04 \%$, F1-score of $79.08 \%$ and accuracy of $79.31 \%$. In addition, we found that (according to our ANN experiments) the main causal factors related to flood susceptibility map only included 3 factors: flow accumulation, elevation, and soil types. Therefore, the proposed methodology for assessment of flood susceptibility areas using these 3 factors could be considered sufficient and applied to other regions in related applications, when needed.
\end{abstract}

Keywords: Analytical hierarchy process, Artificial neuron network, Flood risk assessment, Flood susceptibility mapping, Machine learning

\section{Introduction}

Flooding is one of the major disasters across the globe. It causes not only human and animal death but damages to building infrastructures, the economy, transportation, and agriculture in the affected countries [1]. In Thailand, the 2011 flood, one of the biggest floods in the country, accumulated rainfall about $1,439 \mathrm{~mm}$, which is more than the average rainy season rainfall during 1982 - 2002. It caused 728 deaths, devastated $16,668.55 \mathrm{~km}^{2}$ of agricultural areas and 9,859 factories as well as led to 660,000 job 
losses in 2011 [2,3]. Thanvisitthpon [4] studies the impacts of the monotonous flooding on the residents of the 4 flood-prone regions in Thailand's central province of Ayutthaya.

Flood susceptibility maps, one of the main components of flood risk map calculated by using flood causal/influencing factors [5], has been used to generate maps to create awareness of potential flood disasters in many countries. Several research studies have been done in flood susceptibility and risk assessment using both GIS-based methods [6-10,13] and neural network methods [14-20]. Kourgialas et al. [6] used 6 factors and global climate change scenarios (A2 and B1) to examine flood prone areas. Ozkan and Tarhan [7] studied the prediction of potential flood hazard areas using SRTM-DEM in Izmir province. To perform the spatial analysis of flood hazard areas, 5 factors were used. Moreover, we used a weighting approach and the spatial analysis by assigning different magnitudes of weight to each factor based on the intensity of the effect. Kazakis et al. [8] demonstrated the assessment of flood hazard areas in Greece using Analytical Hierarchy Process (AHP) with 7 factors, and they used the sensitivity analysis to determine the effect of each factor posed on the flood hazard areas. Oikonomidis et al. [9] developed a methodology for assessing the groundwater in Tirnavos, Greece, using 7 factors with AHP and determined the weights of each factor. Their map showed areas of significant groundwater and indicated areas of good quality groundwater. Apart from flood susceptibility map, this geospatial technique could also apply to other susceptibility map. Althuwaynee et al. [10] compared the landslide susceptibility mapping from 4 models: 1) the bivariate model of the Dempster-Shafer based evidential belief function (EBF), 2) EBF AHP using all causal factors, 3) EBF AHP using nominated causal factor weights only, and 4) EBF Logistic Regression using nominated causal factor weights only. The result exhibited that a combination of AHP techniques obtained a better performance than others. The AHP [8-10] is selected as the essential tool in the subjective assessment of the qualitative methods. A pairwise comparison matrix is assigned for the causal factors. It has been applied to calculate relations for each factor and derive weight confirmed by consistency ratio (CR) [11-13]. The accuracy of flood susceptibility maps remains a critical issue although the researched studies $[6-10,13]$ are the most widespread techniques in the geospatial tools.

The advantages of machine learning techniques of flood susceptibility mapping are to help the expert to utilize the resource more efficiently by using previously processed data and can solve classification and regression problems. For occurrence, a machine learning program may successfully pinpoint a causal relationship between 2 variables of Flood Susceptibility Assessment. Vice versa, predictions are limited to the observed cases, and accuracy depends on training and learning, which is not always available [14]. In the literature, the flood susceptibility map has used various machine learning techniques in many research studies. Some of the trendy methods are Artificial Neural Network (ANN), Random Forests (RF) and Support Vector Machines (SVMs) [15-20]. SVMs and RF have been used to assess flood hazard risk assessment by building RF and SVMs models from training sample data. The result showed that the final maps from SVMs and RF were similar [16]. The research study by Melo and Pedrollo [17] used 2 ANN models for estimating the soil water retention curve. The traditional model was compared to a recent ANN approach, the pseudo continuous pedotransfer functions (PTFs). Results indicated that fitted ANNs provided similar statistical indexes in predicting water contents to PTFs method. Tehrany et al. [18] used machine learning (ML) techniques: SVMs and Decision Tree (DT) to identify the essential flood causal factors with 2 data sets for flood prone area mapping. Tehrany et al. [19] used 11 causal factors with weights-of-evidence (WoE) model then, performed with the causal factors through bivariate statistical analysis (BSA) and reclassified using 4 kernel types of SVM: Linear kernel (LN), Polynomial kernel (PL), Radial basis function kernel (RBF), and Sigmoid kernel (SIG). The result of RBF-SVM type was the best, success rate and prediction rate were 96.48 and $95.67 \%$, respectively. Mojaddadi et al. [20] proposed the methodology to estimate the flood probability in Damansara River catchment in Malaysia with 13 flood causal factors, the frequency ratio (FR) was combined with RBF-SVM. Each causal factor was weighted using FR and entered as input for SVM. The results exhibited that the proposed approach could be applied for flood risk management in the study area. However, these types of ML algorithms are prone to over-fit, if the number of features is much greater than the number of samples. This leads to some inconsistent results that lack precision, recall and F1 performance.

Based on the literature, there are 2 main approaches: GIS approach and machine learning approach. In this paper, we adopted and described both methods, with an intention to demonstrate whether or not the machine learning is really efficient and can outperform the traditional GIS approach, so that whichever better will be adopted in practice. Data on Thailand's Ayutthaya Province is used in this work as a case study-in order to assess flood prone areas and compared for performance evaluation. Both methods use the 6 selected factors according to the literature: (i) flow accumulation, (ii) elevation, (iii) land use, (iv) rainfall intensity, (v) slope and (vi) soil types. The remainder of this paper is arranged as follows. Section 2 
describes materials and methods. Section 3 discusses experimental results and discussions. Finally, we conclude our work in section 4.

\section{Materials and methods}

\section{Study area}

There are 21 provinces located in central Thailand (Figure 1). Central Thailand is divided into 3 regions: North Central region, South Central region and Marginal plain region. We selected a representative province for each region; i.e., Ayutthaya from the North Central region, Samut Sakhon from the South Central region, and Lopburi from the Marginal plain region. Selections were based on the highest risk provinces. Historical flood records showed the provinces most severely affected by flooding [GISTDA: Geo-Informatics and Space Technology Development Agency (Public Organization), 2016]. Consequently, Ayutthaya was selected for the study area (Figure 1), because it had the highest damages and losses from the 3 areas: Ayutthaya, Samut Sakhon and Lopburi. Ayutthaya (14²0’N,100³3’E WGS 1984 UTM Zone 47 ) is in the North Central Thailand region; it was the former Thai capital, a prosperous trading port in historical times and is located on the plain of the Chao Phraya River. In addition, Lopburi and Pa Sak Rivers are major sources of the Chao Phraya River, making this province an important rice farming area. Ayutthaya covers an area of 2,557 $\mathrm{km}^{2}$ with 16 districts. There are 3 seasons: summer, rainy and winter.

Temperatures range from average low of $22.3{ }^{\circ} \mathrm{C}$ in March to average high of $35.9{ }^{\circ} \mathrm{C}$ in April. The rainy season starts around June, until the end of October. The average rainfall is $260 \mathrm{~mm}$ in August. Population is 435,353 (https://worldpopulationreview.com). In August 2017, the Thai radio reported that in Ayutthaya's Bang Ban district had been flooded 4 times in 3 months, following an increase in the discharge rate from the Chao Phraya Dam, located above Ayutthaya. Consequently, 6 districts were flooded.
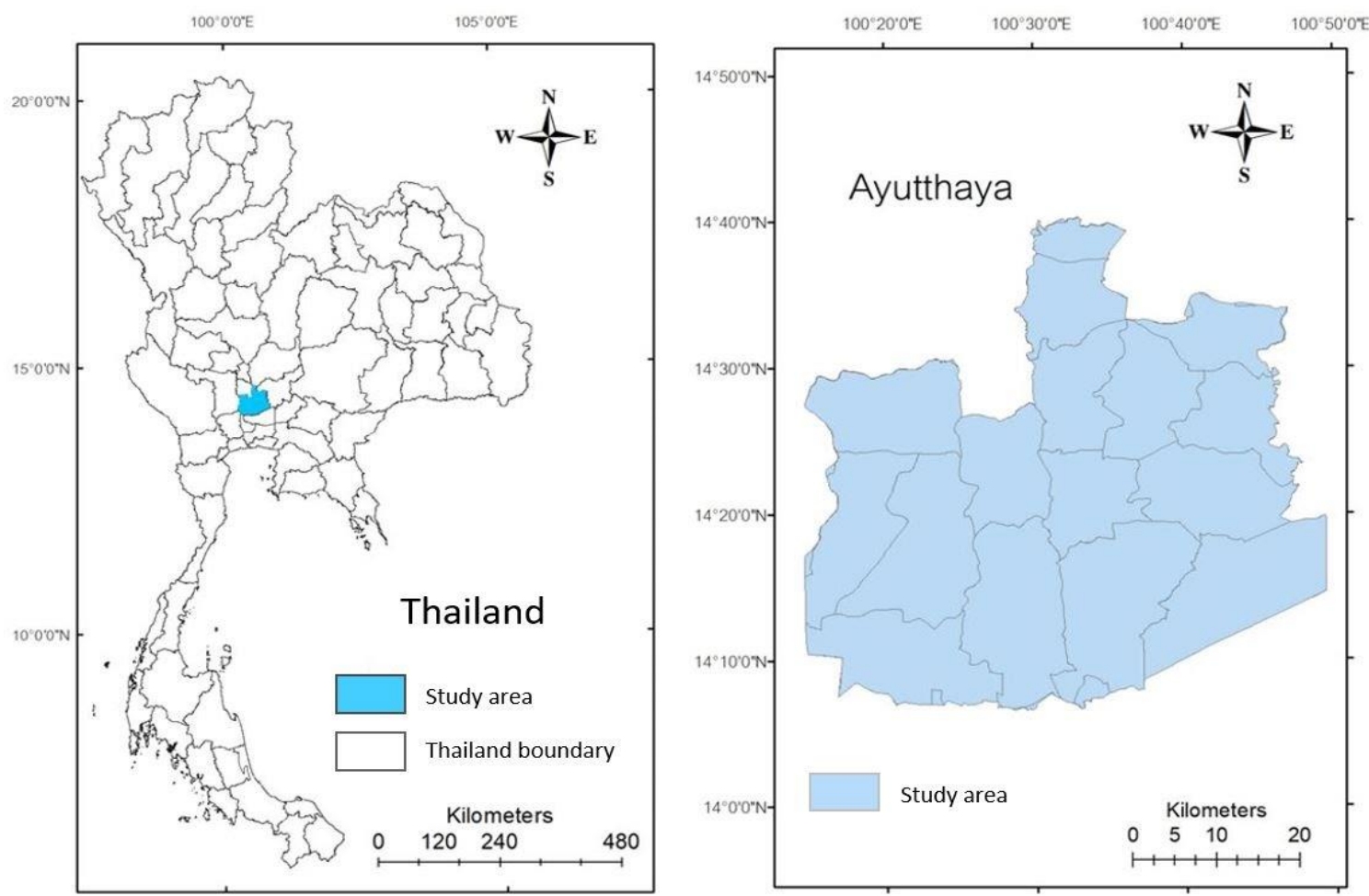

Figure 1 Ayutthaya province, studied area, located in Thailand.

\section{Selected datasets}

The selection of the flood causal factors is one of the important stages in developing the flood susceptibility maps to gain the high precision and reliability. Consequently, this study investigated the previous studies [6-8,21,23] using domain experts, and selected relevant factors to use in this research (Table 1). The selected factors were flow accumulation $(F)$, elevation (E), land use (L), rainfall intensity 
(R), slope (S) and soil types (ST), and they were mapped to generate the susceptibility map. Flow accumulation, elevations and slope were derived from a Digital Elevation Model with 1 arc-second (approximately $30 \mathrm{~m}$ ) resolution (USGS/NASA Shuttle Radar Topography Mission DATA, 2018) in ArcGIS since Thailand does not provide these data. Shuttle Radar Topography Mission (SRTM) is the participant of The National Aeronautics and Space Administration (NASA) and the National GeospatialIntelligence Agency (NGA) responsible to create the global set of land elevations (https://www.usgs.gov/). Flow accumulation factor was used in many research studies [6-8,21] which show hydrological contributions to each raster cell, where the high accumulation was the more flood prone area in that cell [6].

Table 1 The causal factors in previous studies.

\begin{tabular}{|c|c|}
\hline Title & Causal factors \\
\hline $\begin{array}{c}\text { Kourgialas and Karatzas [6] (A flood risk } \\
\text { decision making approach for Mediterranean tree } \\
\text { crops using GIS; climate change effects and flood- } \\
\text { tolerant species) }\end{array}$ & $\begin{array}{l}\text { flow accumulation, slope, rainfall intensity, } \\
\text { elevation, land use and geology }\end{array}$ \\
\hline $\begin{array}{l}\text { Ozkan and Tarhan [7] (Detection of flood } \\
\text { Hazard in Urban areas using GIS: Izmir case) }\end{array}$ & $\begin{array}{l}\text { flow accumulation, slope, rainfall intensity, } \\
\text { elevation and land use }\end{array}$ \\
\hline $\begin{array}{c}\text { Kazakis et al. }[8] \text { (Assessment of flood hazard } \\
\text { areas at a regional scale using an index-based approach } \\
\text { and Analytical Hierarchy Process: Application in } \\
\text { Rhodope-Evros region, Greece) }\end{array}$ & $\begin{array}{l}\text { flow accumulation, rainfall intensity, } \\
\text { elevation, land use, geology and distance } \\
\text { from the drainage network, }\end{array}$ \\
\hline $\begin{array}{l}\text { Mahmoud and Gan [21] (Multi-criteria approach } \\
\text { to develop flood susceptibility maps in arid regions of } \\
\text { Middle East) }\end{array}$ & $\begin{array}{l}\text { flow accumulation, slope, rainfall intensity, } \\
\text { elevation, land use, soil type, geology, runoff, } \\
\text { distance from the drainage network, and } \\
\text { drainage density }\end{array}$ \\
\hline $\begin{array}{c}\text { Seejata [23] (Assessment of flood hazard areas } \\
\text { using analytical hierarchy process over the Lower } \\
\text { Yom Basin, Sukhothai Province) }\end{array}$ & $\begin{array}{l}\text { slope, rainfall intensity, elevation, land use, } \\
\text { soil types, river density }\end{array}$ \\
\hline
\end{tabular}

The areas of low elevation receive runoff from high elevation, which creates the flood susceptibility area. Areas prone to flooding are typically with a low slope degree and low soil water absorption [18]. The data collected from the Land Development Department (LDD) was land-use (L) and soil types (ST). Land use is the factor that indicates the management and modification of the natural environment for settlements. More settlement means more flood prone areas since deforestation and economic growth [24]. Type of soil refers to permeability of different soil. High soil permeability showed sites with very low flood susceptibility, whereas low permeability areas had very high susceptibility flood zones. Rainfall intensity (R) was collected from 12 stations of the Thai Meteorological Department (TMD), over a period of 5 years (2013 - 2017). It is the rate or volume of the precipitation at a given time [25].

\section{Flood inventory mapping}

The historical flood data indicated flood areas (as shown in Figure 2 in light blue) in the study areas used in this study. They were captured by Thailand's earth observation satellite (THEOS) which were investigated by image processing and recorded into the satellite database. Afterward, each image of THEOS was analyzed and integrated with other relevant data: Land use mapping and topographic model, and then overlay with Ayutthaya Province for created historical flood data (GIS database) in 2016, which was provided by Geo- Informatics and Space Technology Development Agency (GISTDA) (https://flood.gistda.or.th) of the Thai Government. 


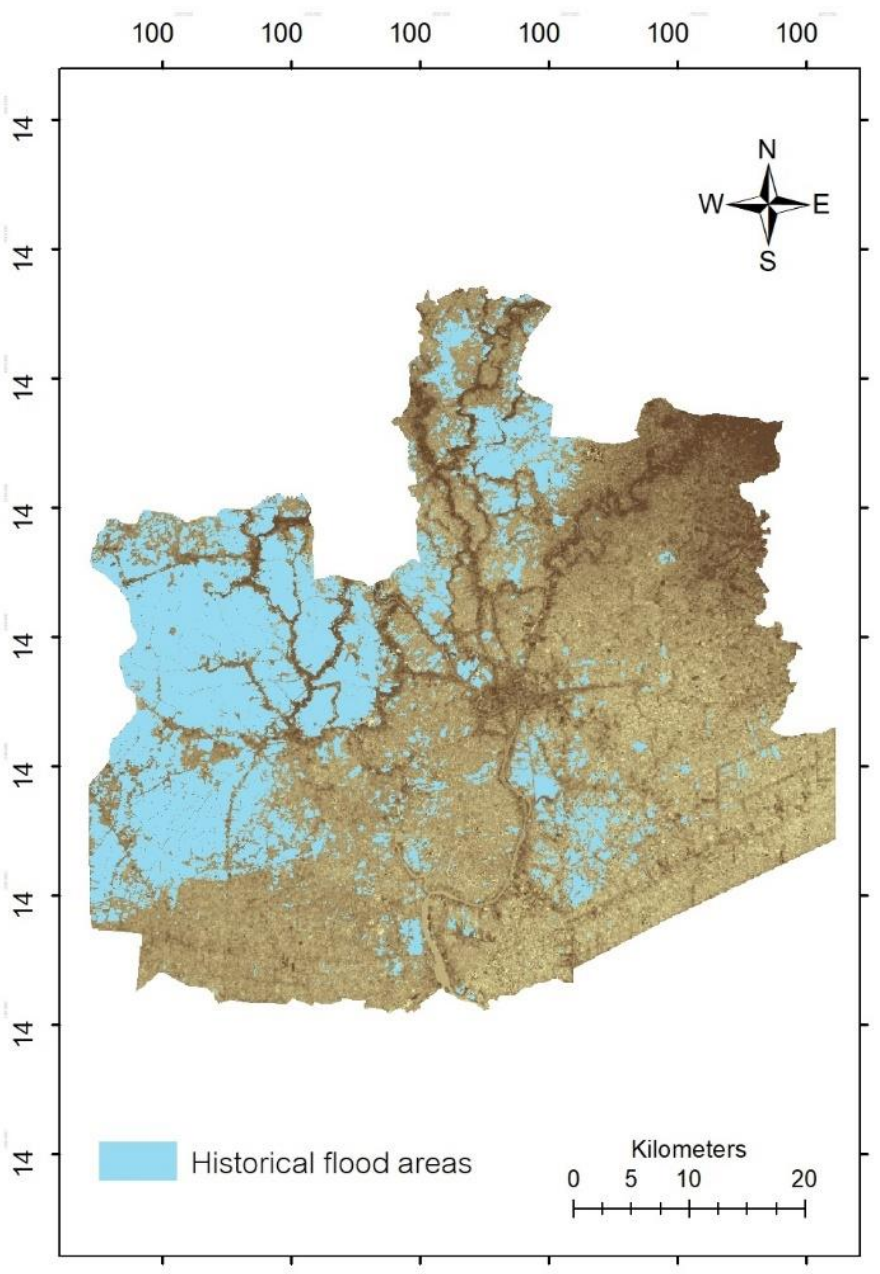

Figure 2 The historical flood zone shows flood events, which were captured in 2016 from GISTDA. Most of the flooding areas are located in the west of the study area.

\section{Proposed methodology}

The FRAM model was selected, generated by ArcGIS, which had 6 factors: F, E, L, R, S, ST and weights. FRAM was represented by:

$\mathrm{FRAM}=\sum_{i=1}^{n} r_{i} w_{i}=\mathrm{F} \cdot w_{F}+\mathrm{E} \cdot w_{E}+\mathrm{L} \cdot w_{L}+\mathrm{R} \cdot w_{R}+\mathrm{S} \cdot w_{S}+\mathrm{ST} \cdot w_{S T}$

where $r_{i}$ is the rating of $i^{\text {th }}$ factor, $w_{i}$ is the associated weight of each factor ( $i=\mathbf{F}, \mathbf{E}, \mathbf{R}$, etc) and $\mathbf{n}$ is the number of factors. Reclassification of the factor values into 5 risk classes, following other research and domain experts in this research domain which also used 5 classes [6-8,21,23]: Very high, high, medium, low and very low which were determined by factor ratings of 10, 8, 6, 4 and 2 (Table 5). AHP was used for deriving the final map. The first step arranges the factors in rows and columns. Each factor was given a value between 1 and 9 (Table 2), when compared to the other factors [6]. In this case, a pairwise comparison in a $6 \times 6$ matrix, where $a_{i j}=k$ then $a_{j i}=1 / k ; i=1,2,3, \ldots, n$ and $j=1,2,3, \ldots, n$. To form this matrix (Table 3) was produced, assigned values based on a ranking of the importance of each factor, taken from an expert [23]. For example, flow accumulation is more important than rainfall intensity, therefore assigned the value 3. On the other hand, rainfall intensity is the reciprocal of the pairwise comparison (e.g., 1/3 for rainfall intensity and so forth). 
Table 2 Description of assigned values.

\begin{tabular}{|c|c|c|}
\hline Ranking & Meaning/Significance & Description \\
\hline 1 & Equally important & Both factors are equally important \\
\hline 3 & Medium important & One factor has adequately more importance level than the other \\
\hline 5 & High important & One factor has significantly more importance level than the other \\
\hline 7 & The highest important & One factor has the highest importance level than the other \\
\hline 9 & $\begin{array}{l}\text { More than the highest } \\
\text { important }\end{array}$ & $\begin{array}{l}\text { One factor has more importance level than the highest range } \\
\text { compare to the other }\end{array}$ \\
\hline $2,4,6,8$ & Within the range above & The factors are within the range above. \\
\hline
\end{tabular}

Table 3 Pairwise comparisons for each factor.

\begin{tabular}{ccccccc}
\hline & $\begin{array}{c}\text { flow } \\
\text { accumulation }\end{array}$ & elevation & $\begin{array}{c}\text { land } \\
\text { use }\end{array}$ & rainfall & slope & $\begin{array}{c}\text { soil } \\
\text { types }\end{array}$ \\
\hline $\begin{array}{c}\text { flow } \\
\text { accumulation }\end{array}$ & 1 & 2 & 3 & 3 & 5 & 2 \\
\hline elevation & $1 / 2$ & 1 & 3 & 3 & 4 & $1 / 3$ \\
\hline land use & $1 / 3$ & $1 / 3$ & 1 & 2 & 4 & $1 / 6$ \\
\hline rainfall & $1 / 3$ & $1 / 3$ & $1 / 2$ & 1 & 4 & 2 \\
\hline slope & $1 / 5$ & $1 / 4$ & $1 / 4$ & $1 / 4$ & 1 & $1 / 2$ \\
\hline soil types & $1 / 2$ & 3 & 6 & $1 / 2$ & 2 & 1 \\
\hline
\end{tabular}

The Consistency Ratio (C.R.) checks whether the obtained weights were appropriate or not:

C.R. $=\frac{\text { C.I. }}{\text { R.I. }}$

where C.I. $=$ the consistency index and R.I. $=$ a random index. The R.I. values depend on a number of factors which were calculated previously $[11,12]$. Therefore, R.I. $=1.24$, because it had 6 factors, $\mathrm{N}=6$ as shown in Table 4.

Table 4 Random index values depend on the number of factors.

\begin{tabular}{ccccccccccc}
\hline $\mathbf{N}$ & 1 & 2 & 3 & 4 & 5 & $6 \ldots \ldots$ & 12 & 13 & 14 & 15 \\
\hline R.I. & 0 & 0 & 0.58 & 0.9 & 1.12 & $1.24 \ldots$ & 1.48 & 1.56 & 1.57 & 1.59 \\
\hline
\end{tabular}


The Consistency Index (C.I) was calculated:

C.I. $=\frac{\lambda_{\max }-n}{n-1}$

where $\lambda_{\max }$ is the maximum eigenvalue of the comparison matrix. In the matrix in Table $\mathbf{3}, \lambda_{\max }=6.58$, $\mathrm{n}=6$. Therefore C.I. $=0.116$ and the calculated Consistency Ratio from equation 2 was 0.09. Since C.R. less than 0.1 , the calculated weights were accepted $[11,12]$.

Table 5 Classes of the flood factors and rating each factor.

\begin{tabular}{|c|c|c|c|}
\hline Number & Thematic layers & Class ranges & Rating \\
\hline \multirow[t]{5}{*}{1} & flow accumulation & $55,401-71,300$ & 10 \\
\hline & & $25,501-55,400$ & 8 \\
\hline & & $10,301-25,500$ & 6 \\
\hline & & $2,501-10,300$ & 4 \\
\hline & & $0-2,500$ & 2 \\
\hline \multirow[t]{5}{*}{2} & elevation (m) & $0.00-2.00$ & 10 \\
\hline & & $2.10-4.00$ & 8 \\
\hline & & $4.10-6.00$ & 6 \\
\hline & & $6.10-9.00$ & 4 \\
\hline & & $9.10-35.00$ & 2 \\
\hline \multirow[t]{5}{*}{3} & land use & Water & 10 \\
\hline & & Agriculture & 8 \\
\hline & & Urban & 6 \\
\hline & & Miscellaneous & 4 \\
\hline & & Forest & 2 \\
\hline \multirow[t]{5}{*}{4} & rainfall intensity & $4,931-7,000$ & 10 \\
\hline & & $3,341-4,930$ & 8 \\
\hline & & $1,901-3,340$ & 6 \\
\hline & & $546-1,900$ & 4 \\
\hline & & $0-545$ & 2 \\
\hline \multirow[t]{5}{*}{5} & slope & $0-0.40$ & 10 \\
\hline & & $0.41-0.70$ & 8 \\
\hline & & $0.71-1.20$ & 6 \\
\hline & & $1.21-2.00$ & 4 \\
\hline & & $2.10-8.00$ & 2 \\
\hline
\end{tabular}




\begin{tabular}{cccc}
\hline Number & Thematic layers & Class ranges & Rating \\
\hline 6 & soil types & Worst & 10 \\
& & Bad & 8 \\
& Medium & Good & 4 \\
& Very Good & 2 \\
\hline
\end{tabular}

\section{Discretization}

After deriving the weights for each of the causal factors, these factors were calculated from equation 4 using the derived weights (Table 6). Then using the spatial analyst tool of ArcGIS and the calculated factors were added using a raster calculator to reclassify and produce the flood susceptibility zones.

$\mathrm{FRAM}=\mathrm{F} \times 2.9+\mathrm{E} \times 1.8+\mathrm{L} \times 1.1+\mathrm{R} \times 1.4+\mathrm{S} \times 0.5+\mathrm{ST} \times 2.3$

Table 6 Normalized flood factors: Analytical hierarchy process.

\begin{tabular}{ccccccccc}
\hline & $\begin{array}{c}\text { flow } \\
\text { accumulation }\end{array}$ & elevation & $\begin{array}{c}\text { land } \\
\text { use }\end{array}$ & rainfall & slope & $\begin{array}{c}\text { soil } \\
\text { types }\end{array}$ & mean & weight \\
\hline $\begin{array}{c}\text { flow } \\
\text { accumulation }\end{array}$ & 0.35 & 0.29 & 0.22 & 0.31 & 0.22 & 0.33 & 0.29 & 2.90 \\
elevation & 0.17 & 0.14 & 0.22 & 0.31 & 0.21 & 0.06 & 0.18 & 1.80 \\
$\begin{array}{c}\text { land use } \\
\text { rainfall }\end{array}$ & 0.12 & 0.05 & 0.07 & 0.20 & 0.18 & 0.03 & 0.11 & 1.10 \\
slope & 0.12 & 0.05 & 0.03 & 0.10 & 0.21 & 0.33 & 0.14 & 1.40 \\
$\begin{array}{c}\text { soil types } \\
\text { summation } \\
\text { row }\end{array}$ & 0.07 & 0.04 & 0.02 & 0.03 & 0.07 & 0.08 & 0.05 & 0.50 \\
\hline
\end{tabular}

The value in each factor was assigned to 10 (Red zone), if it was a high flood prone area. On the other hand, the value was assigned to 2 for low flood susceptibility areas. The updated maps (Figure 3) show the spatial distributions of these factors. 

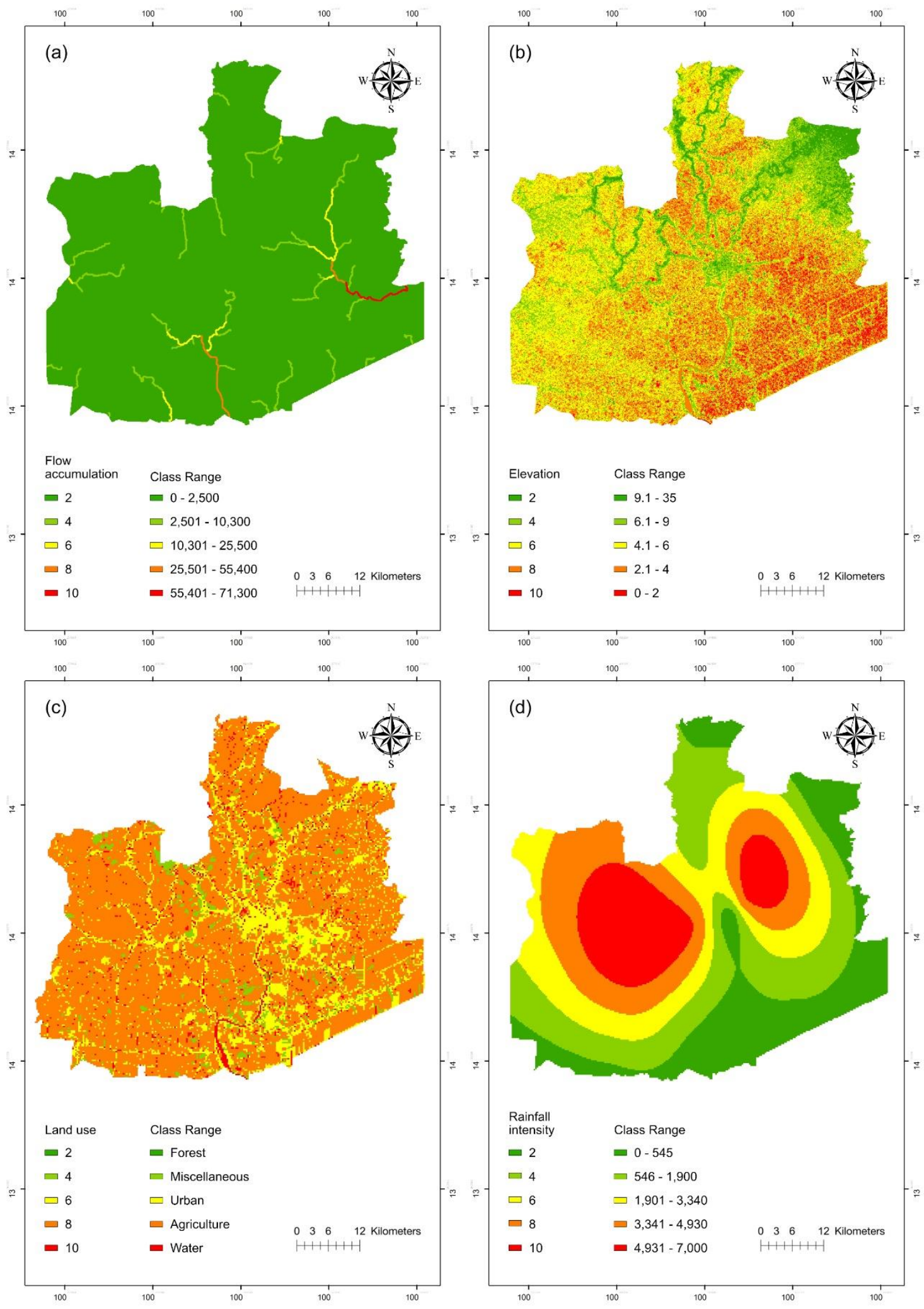


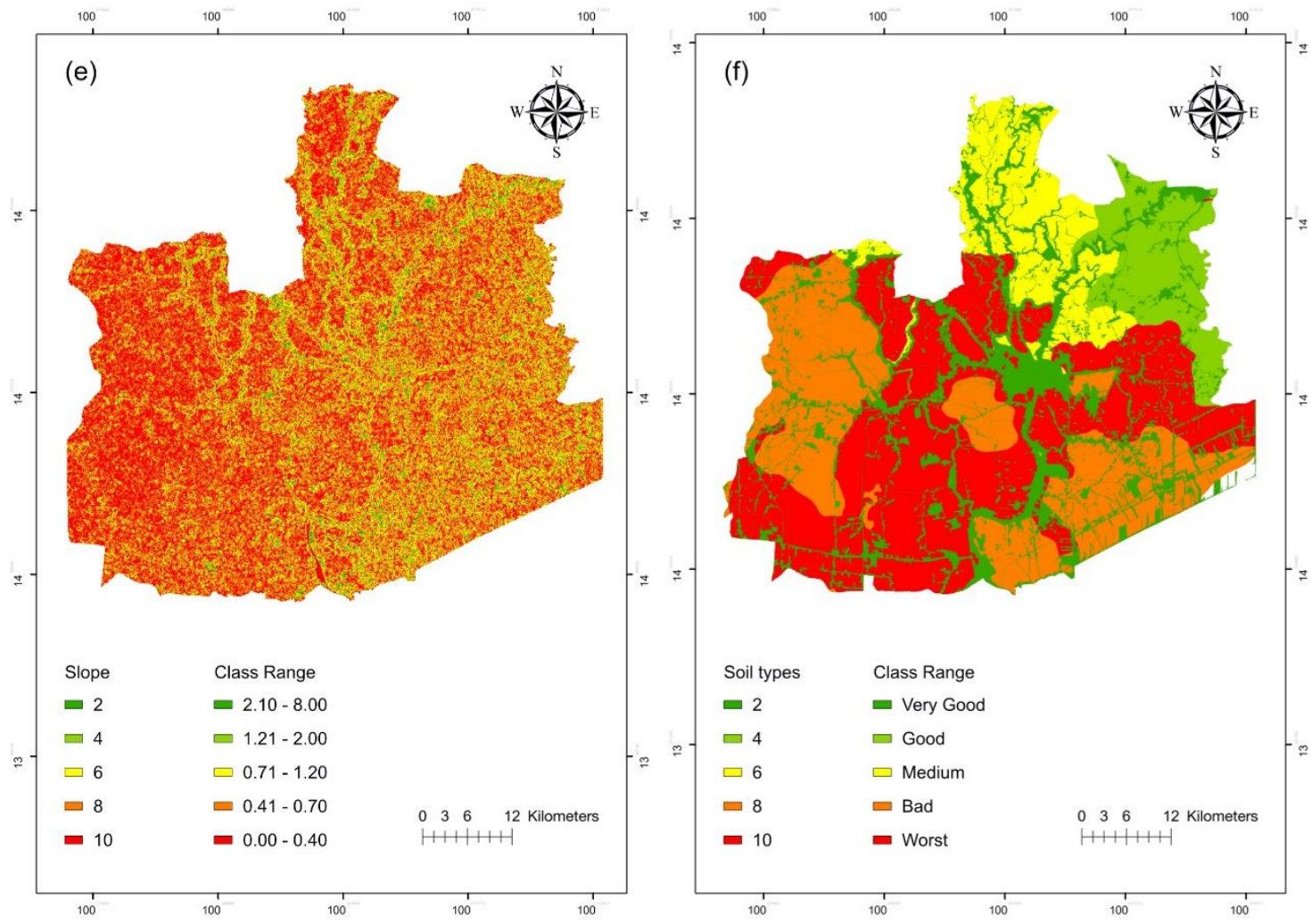

Figure 3 Flood causal factors; (a) flow accumulation, (b) elevation, (c) land use, (d) rainfall intensity, (e) slope, (f) soil types.

\section{Artificial neural networks}

Artificial neural networks (ANN) are one of the main algorithms used in machine learning. They consist of an input layer, an output layer, and one or more hidden layers. There are connections between layers. Each connection has a weight that can be adjusted during training process. The inputs and outputs of a neural network are represented by input and output neurons. They are practical methods for finding complex patterns, which a machine can recognize after training.

Once a neural network has been structured for a particular application, that network is ready to be trained. To start this process, the initial weights are not chosen randomly, and we use "HeUniform" as initializers. Then the training the model begins. We created an ANN model to predict floods from 6 factors: F, E, L, R, S and ST. Before creating the model, we prepared the data in a pre-processing step. In this step, we cleaned all the data and concatenated all files into data frames using Python's Pandas library. However, the data still had missing values: in the target column, we used 1.0 for flood areas and 0.0 for flood free areas and all missing values were filled by means of all data in that column: see the example filled in data in Table 7. We found that dealing with the missing value with mean value is the most robust approximation in many research fields. We performed best in preserving the precision of the meta-analysis findings, although in some situations, disregarding trials gave superior results. Other methods based on core statistics (median, mode, minimum, maximum, lower, and upper quartile) described in the literature facilitate more extensive inclusion of randomized controlled trials with missing mean [26]. 
Table 7 Example data with missing values filled in.

\begin{tabular}{|c|c|c|c|c|c|c|c|c|}
\hline lon & $\begin{array}{l}\text { Rainfall } \\
\text { intensity }\end{array}$ & elevation & $\begin{array}{c}\text { flow } \\
\text { accumulation }\end{array}$ & $\begin{array}{l}\text { land } \\
\text { use }\end{array}$ & lat & slope & $\begin{array}{l}\text { soil } \\
\text { types }\end{array}$ & target \\
\hline 14.22250 & 2727.67 & 6.00 & 544.03 & 6.88 & 100.24333 & $7.36 \mathrm{E}+33$ & 1.57 & 0.00 \\
\hline 14.22333 & 2727.67 & 5.00 & 544.03 & 6.88 & 100.24333 & $7.36 \mathrm{E}+33$ & 1.57 & 0.00 \\
\hline 14.22417 & 2727.67 & 8.00 & 544.03 & 6.88 & 100.24333 & $7.36 \mathrm{E}+33$ & 1.57 & 0.00 \\
\hline 14.22500 & 2727.67 & 6.00 & 544.03 & 6.88 & 100.24333 & $7.36 \mathrm{E}+33$ & 1.57 & 0.00 \\
\hline 14.22583 & 2727.67 & 7.00 & 544.03 & 6.88 & 100.24333 & $7.36 \mathrm{E}+33$ & 1.57 & 0.00 \\
\hline
\end{tabular}

Note: Gray values are missing values that were filled in.

After pre-processing, the next step was data modelling, since the data we had was unbalanced: We had 192 historical flood data points from GISTDA with a much higher resolution set of data points, which was assembled from many sources. We used all historical flood data to mark as flood areas that mapped with causal factors by latitude and longitude data. The remaining points also were marked as flood free areas with the same size and methodology by randomizing the data. For training the neural net, the 192 flood points together with 192 flood free points (keep a balance between flood and flood free areas) from the larger set, giving a total of 384 samples in the training set. From this data, $70 \%$ was selected as the training set and $30 \%$, as the test set for the created neural net (neural network model consists of 7 inputs, 22 hidden layer sizes and 2 outputs. Activation is ReLU and Optimizer is Adam.). Cross validation, one of the model validation techniques, was selected for our modelling, on the basis of reliability and suitable for insufficient data. Initially, for the cross-validation method, the training set was divided into $\mathrm{n}$ folds: Onefold used for validation and the remaining n-1 fold for training. Our training set was divided into 10 random groups. For the initial iteration, folds 2,3 to 10 were used as the training set, while fold 1 was used as the validation set. The experiment was conducted on Google COLAB [27] with initial parameters: activation function $=$ ReLU; alpha (default L2 penalty or regularization term) $=0.0001$, batch_size $=$ auto; epsilon $=$ $10^{-8}$ for numerical stability in the Adam solver [28] hidden layer sizes $=22$; constant learning rate $=0.001$; maximum number of iterations allowed. The seed was 1992. The solver iterated until convergence or 500 epochs.

\section{Results and discussions}

Flood risk assessment model

This model (FRAM) used AHP method for estimation of the weights and applied to the flood susceptibility maps with 6 factors (F, E, L, R, S and ST), according to Eq. (1). The result (as demonstrated in Figure 4) showed that the flood susceptibility map representing the very high and high flood prone areas was located in the west, southeast and central regions as indicated by each of the 4 factors (S, L, R, and ST) (see Figure 3). 


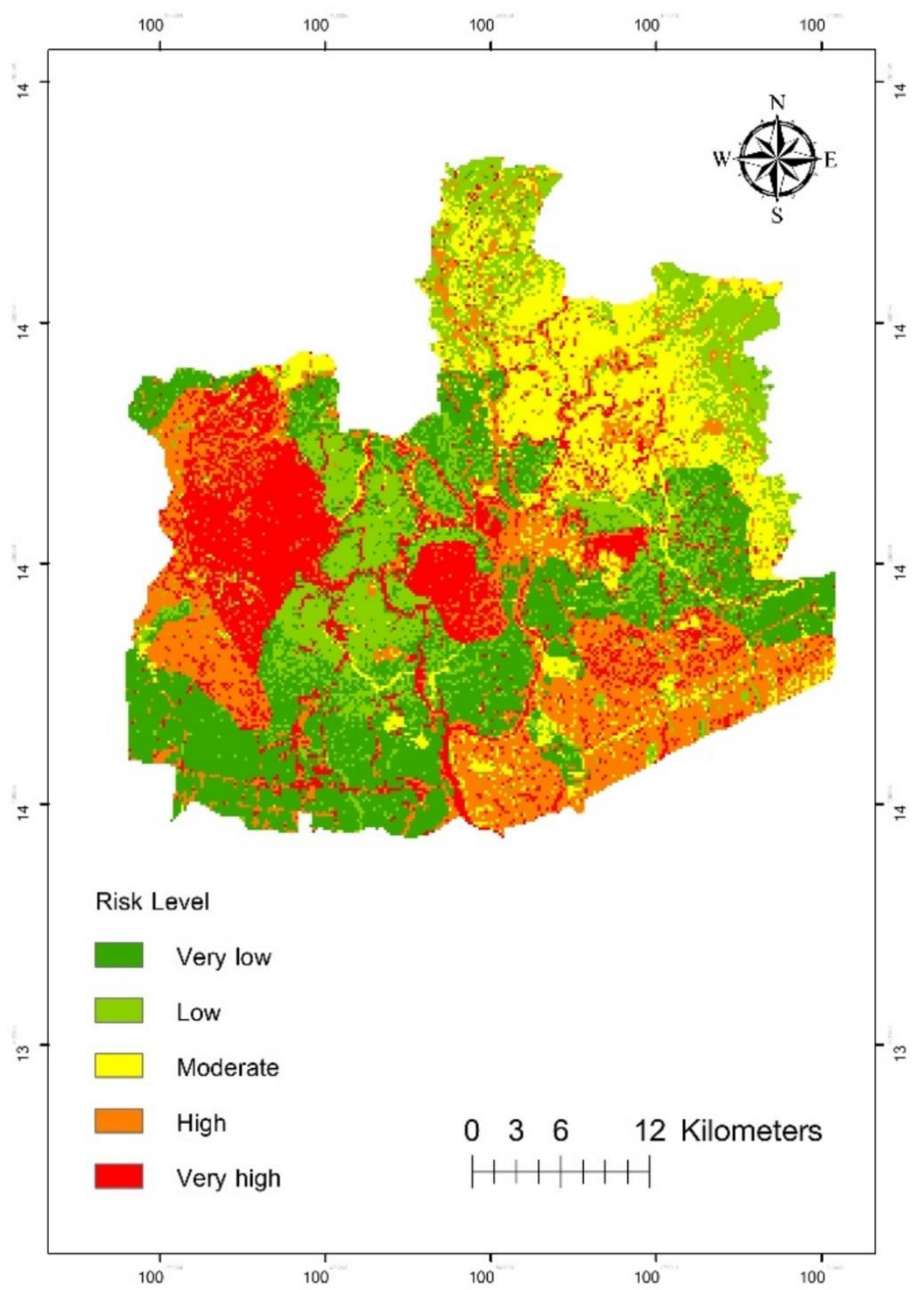

Figure 4 Flood susceptibility map from the flood risk assessment model (FRAM).

In addition, these 4 factors (S, L, R and ST) in the updated maps (as shown in Figure 3) showed very high and high flood prone areas located in the west, southeast and central regions of Ayutthaya whereas medium, low and very low risk was found in the other regions Therefore, the combination of the analysis between FRAM and updated maps showed a similar direction that made this model more reliable.

\section{Comparison between FRAM and historical flood data}

Historical flood data (light blue areas in Figure 2), for flood events in the Ayutthaya region used here was captured in 2016. The majority of the flooded areas were located in the west of the study area, at low elevations and with a low degree of topographic slope. In this section, we verified FRAM against the historical data separated into 2 types of areas: Flood and flood-free areas. For this purpose, from historical data, we evaluated FRAM into 2 types; type 1 includes all factors, type 2 exclude ' $S$ ', ' $R$ ', and ' $L$ ' factors and classifies regions into 4 classes: TP, TN, FP and FN. Type 1: (i) TP was $16.79 \%$, TN was $44.71 \%$, FP was $24.08 \%$ and FN is $14.40 \%$. Type 2: (i) TP was $12.36 \%$, TN was $18.62 \%$, FP was $50.17 \%$ and FN was $18.83 \%$ (Table 8) indicating matches between historical and FRAM data over data points available 
in the historical data, where TP and TN are the correctly classified to the flood and flood-free areas class, respectively. FP and FN are erroneously classified. Then, we computed the confusion matrix to estimate precision, recall, F1-score and accuracy (Table 10).

Table 8 Percentage of FRAM against the historical flood data.

\begin{tabular}{lcc}
\hline & \multicolumn{2}{c}{ T1 (6 factors)/T2 (3 factors) } \\
\cline { 2 - 3 } & Actually positive & Actually negative \\
\hline Predict positive & $16.79 / 12.36 \%$ & $24.08 / 50.17 \%$ \\
\hline Predict negative & $14.40 / 18.83 \%$ & $44.71 / 18.62 \%$ \\
\hline
\end{tabular}

Note: $T 1$ refers with all factors and $T 2$ refers without 'S', 'R', and ' $L$ ' factors.

\section{Model evaluation}

Our implementation used the sk-learn library [29]. All experiments used a 2vCPU @ 2.2GHz,13GB RAM to evaluate Precision, Recall and F1-Score. Precision was the classifier's ability to predict positives, calculated as the ratio of correctly predicted positives to the total predicted positives. Recall is the number of positive samples that were classified as positive, calculated by the ratio of correctly predicted positives to the total actual positives. The F1-Score is used to measure the overall performance of the model. The 3 metrics are calculated as:

Precision $=\frac{\text { TruePositive }}{\text { TruePositive }+ \text { FalsePositive }}$

Recall $=\frac{\text { TruePositive }}{\text { TruePositive }+ \text { FalseNegative }}$

F1-score $=\frac{2 \times \text { Precision } \times \text { Recall }}{\text { Precision }+ \text { Recall }}$

\section{Sensitivity analysis}

Table 9, we assessed the performance of the model by dividing into 4 types. We suggest that the results in Macro average are suitable for this experiment. In Type 1 scenario with all factors, the precision obtained from this ANN model was 0.77, recall was 0.53, F1-Score was 0.42 and accuracy was 0.57 from 28 supports. Type 2 scenario excluding ' $S$ ' factor, the statistical factors: Precision, recall, F1-Score were 0.78 and accuracy was 0.79 from 29 supports. Type 3 scenario in which ' $S$ ' and ' $R$ ' was not included, the precision was 0.77 , recall was $0.71, \mathrm{~F} 1$-Score was 0.70 and accuracy was 0.72 from 29 supports. The last is Type 4 scenario in which ' $S$ ', ' $R$ ' and ' $L$ ' was eliminated, precision, recall, F1-Score and accuracy were 0.79 from 29 supports. 
Table 9 Neural nets performance.

\begin{tabular}{|c|c|c|c|c|c|}
\hline & & Precision & Recall & F1-score & Support \\
\hline & & T1/T2/T3/T4 & T1/T2/T3/T4 & T1/T2/T3/T4 & T1/T2/T3/T4 \\
\hline $\begin{array}{c}\text { Flood free } \\
\text { areas }\end{array}$ & $(0.00)$ & $\begin{array}{c}1.00 / 0.83 \\
/ 0.87 / 0.83\end{array}$ & $\begin{array}{c}0.07 / 0.83 \\
/ 0.50 / 0.71\end{array}$ & $\begin{array}{c}0.14 / 0.83 \\
/ 0.63 / 0.76\end{array}$ & $\begin{array}{c}13 / 18 \\
/ 14 / 14\end{array}$ \\
\hline Flood areas & $(1.00)$ & $\begin{array}{c}0.55 / 0.72 \\
/ 0.66 / 0.76\end{array}$ & $\begin{array}{c}1.00 / 0.72 \\
/ 0.93 / 0.86\end{array}$ & $\begin{array}{c}0.71 / 0.72 \\
/ 0.77 / 0.81\end{array}$ & $\begin{array}{l}15 / 11 \\
/ 15 / 15\end{array}$ \\
\hline Accuracy & & - & - & $\begin{array}{c}0.57 / 0.79 \\
/ 0.72 / 0.79\end{array}$ & $\begin{array}{c}28 / 29 \\
/ 29 / 29\end{array}$ \\
\hline Macro average & & $\begin{array}{c}0.77 / 0.78 \\
/ 0.77 / 0.79\end{array}$ & $\begin{array}{c}0.53 / 0.78 \\
/ 0.71 / 0.79\end{array}$ & $\begin{array}{c}0.42 / 0.78 \\
/ 0.70 / 0.79\end{array}$ & $\begin{array}{c}28 / 29 \\
/ 29 / 29\end{array}$ \\
\hline $\begin{array}{l}\text { Weighted } \\
\text { average }\end{array}$ & & $\begin{array}{c}0.76 / 0.79 \\
/ 0.76 / 0.79\end{array}$ & $\begin{array}{c}0.57 / 0.79 \\
/ 0.72 / 0.79\end{array}$ & $\begin{array}{c}0.44 / 0.79 \\
/ 0.70 / 0.79\end{array}$ & $\begin{array}{c}28 \text { / } 29 \\
/ 29 \text { / } 29\end{array}$ \\
\hline
\end{tabular}

Note: T1, T2, T3 and T4 refer respectively to type of the analysis (i) with all factors included (ii) without 'S' factor; (iii) without ' $S$ ' and 'R' factors; and (iv) without 'S', 'R', and 'L' factors; '-' refers to no data.

Table 10 compares the performance on FRAM vs ANN including 3 factors, the results of FRAM exhibited that precision, recall, F1-Score and accuracy were $0.20,0.39,0.26$ and 0.31 , respectively. On the contrary, all statistical values of ANN were 0.79. It is clear that assessment of flood susceptibility areas with the ANN model performed better than FRAM on all metrics.

Table 10 FRAM vs ANN performance- without S, R and L factors.

\begin{tabular}{ccccc}
\hline & Precision & Recall & F1-Score & Accuracy \\
\hline FRAM & 0.20 & 0.39 & 0.26 & 0.31 \\
ANN & 0.79 & 0.79 & 0.79 & 0.79 \\
\hline
\end{tabular}

\section{Model validation}

The challenge of measuring performance in a neural network is critical. As a result, we rely on an AUC - ROC Curve for a classification problem. The AUC (Area Under the Curve) and ROC (Receiver Operating Characteristics) curves are used to verify or depict the performance of a multi-class classification task. It is one of the essential assessment measures for assessing the performance of any classification model.

Consider the binary classification, where the results are classified as either positive (p) or negative (n). A binary classifier can produce four different results. A TP is counted when the result of a prediction is $\mathrm{p}$, and the actual value is also p; however, an FP is counted instead if the actual value is $\mathrm{n}$. When the predicted outcome and the actual value are $\mathrm{n}$, a TN will be counted, and when the prediction outcome is $\mathrm{n}$, but the actual value is $\mathrm{p}$, an FN will be counted.

As $x$ and y axes, the False Positive Rate (FPR) and True Positive Rate (TPR) create an ROC space that displays relative trade-offs between TPR and FPR. In the ROC space, each prediction result or occurrence of a confusion matrix represents one point. Because TPR equals sensitivity and FPR equals 1 specificity, the ROC graph is also called the sensitivity vs. (1 - specificity) plot. 


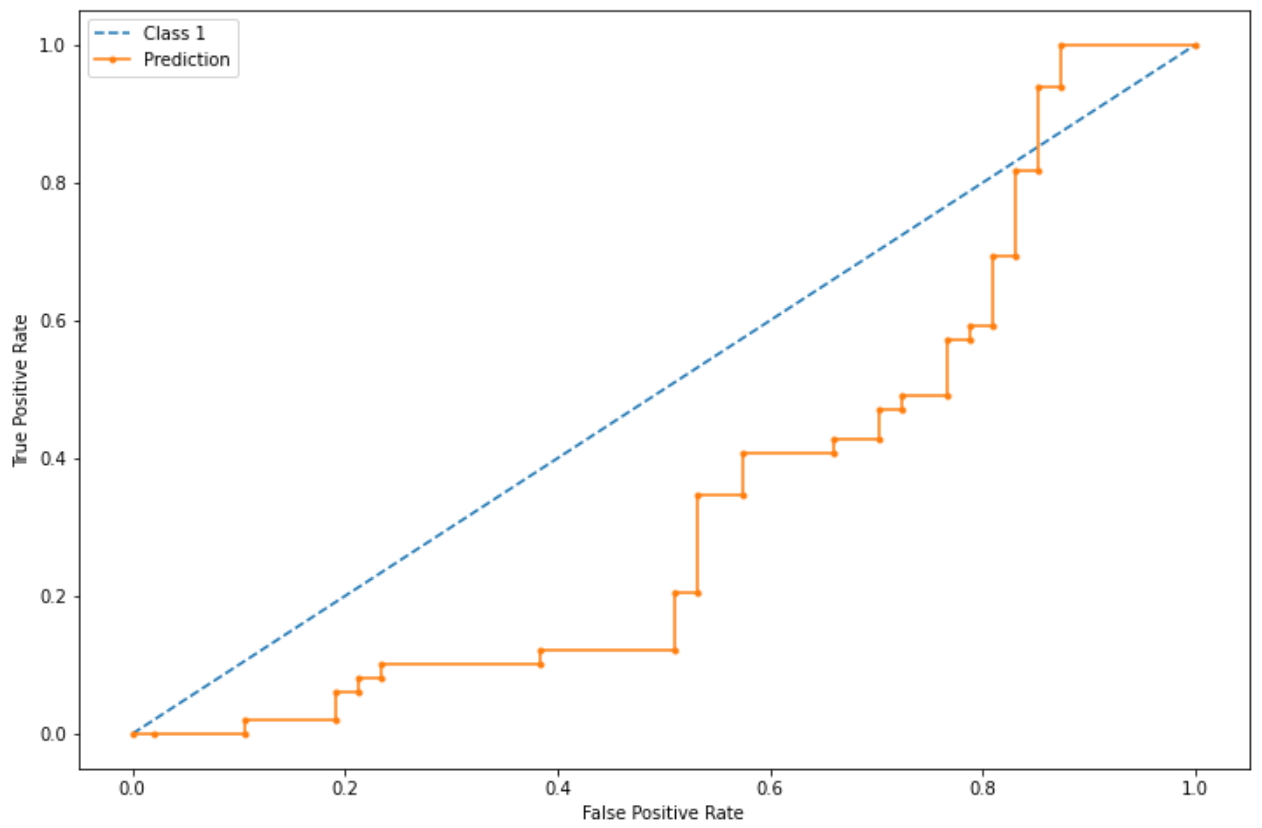

Figure 5 ROC curve with 6 factors to validate flood susceptibility map.

From Figure 5, the estimated AUC for the test set was 0.34, which indicates a 'poor' prediction accuracy. The oblique crosses the ROC space. Scores above the diagonal represent high-grade classification results (more useful than accidental); scores below the line describe unsatisfactory results (worse than random). See that the output of a consistently wrong predictor could be inverted to become a trustworthy predictor. Thus, it is likely to determine the AUC by using an average of several trapezoidal estimates.

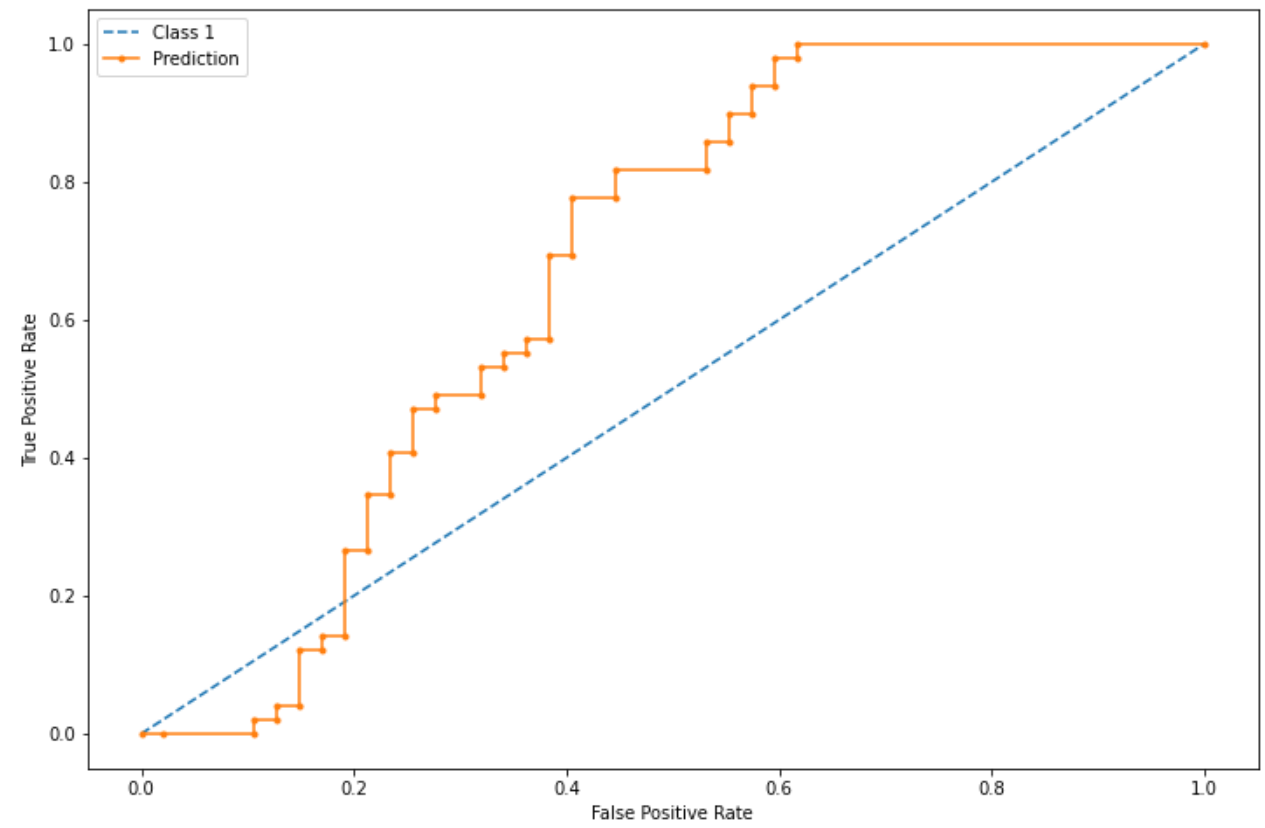

Figure 6 ROC curve without slope factor to validate flood susceptibility map. 


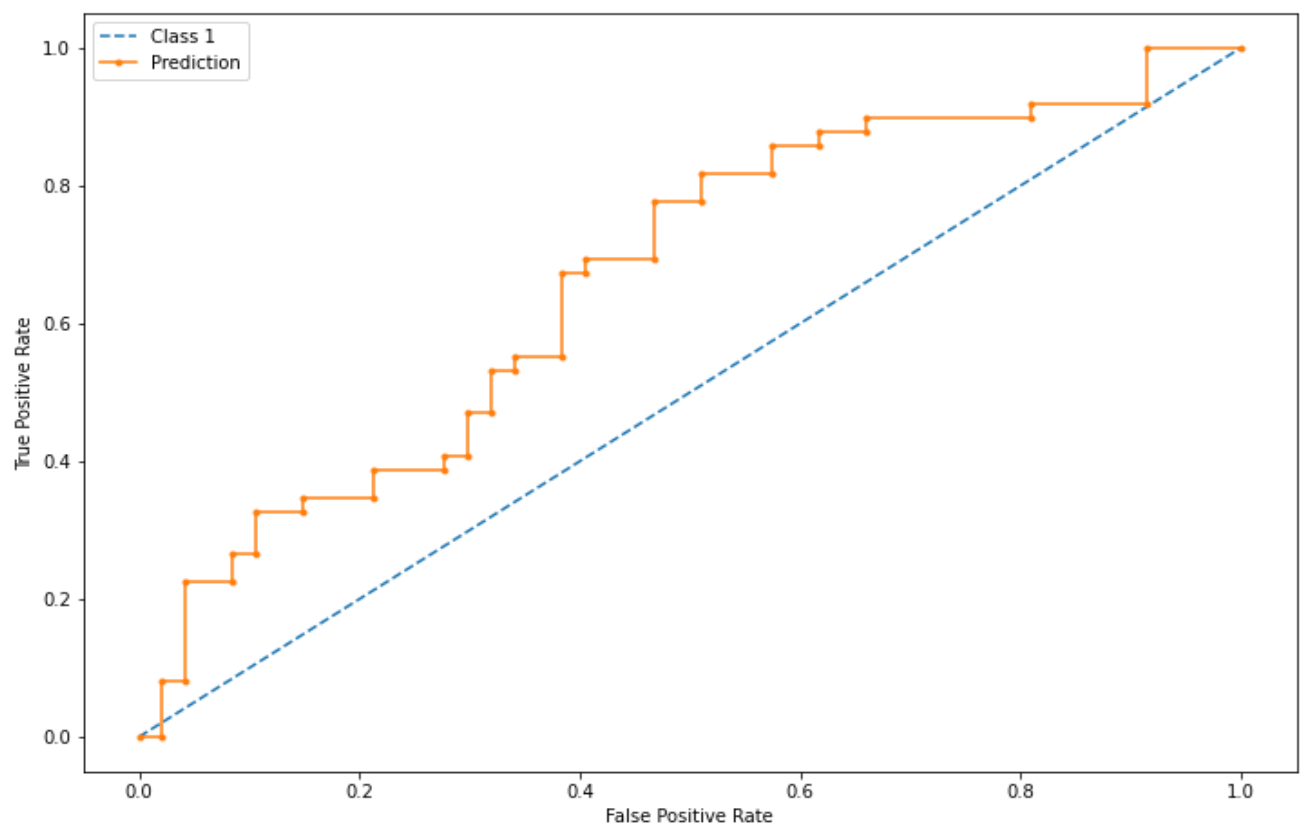

Figure 7 ROC curve without slope and rainfall factors to validate flood susceptibility map.

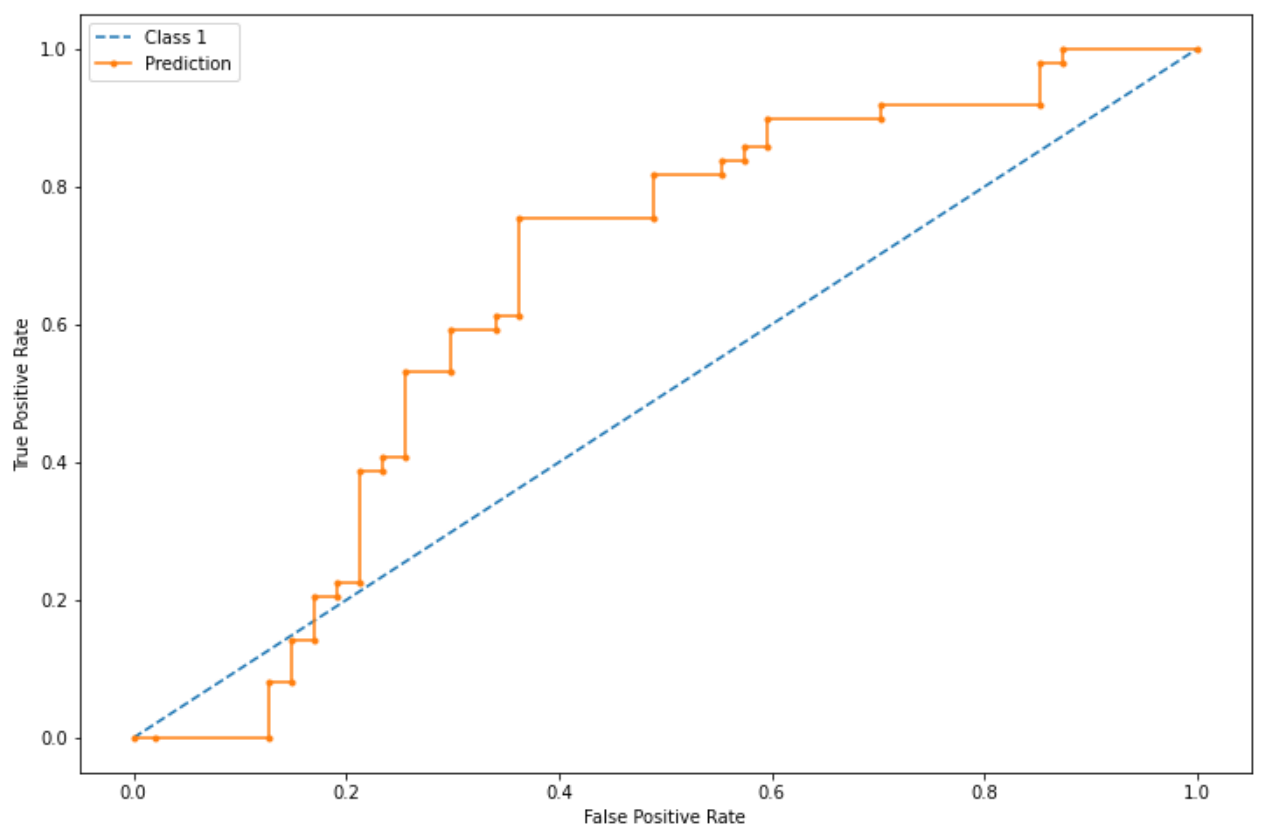

Figure 8 ROC curve without slope, rainfall and land use factors to validate flood susceptibility map.

In Figure 6, the ROC curve for the classification without slope factor is illustrated. The estimated AUC for the testing set was 0.67 . Likewise, the performance of the classification without slope and rainfall factors is illustrated in Figure 7, and the estimated AUC 0.66. In Figure 8, the ROC curve represents the performance of the classification without slope, rainfall and land use factors. The estimated AUC was 0.65 .

For techniques to prevent overfitting, the ANN model applies the cross-validation technique as a powerful preventative measure against overfitting. Also, the ROC graph for the constructed model from Figure 8, AUC exhibits a value of 0.65 , which is a high score. So, the performance evaluation methods confirmed the reliability of the model. Moreover, our ANN model has learned the training data and testing too well. 
The aim of our research was to evaluate the prediction of the flood susceptibility map by using the ANN technique compared with the FRAM, which was the traditional method. The traditional method or flood risk assessment model was popular among many research studies $[6,8,21,23]$. However, there is a drawback in terms of precision and accuracy, the resulted percentage of FRAM against the historical flood data exhibited that the correctly predicted results were only $16.79 \%$ compared to the actual values. This means the performance of predicting flood areas class resulted in poor efficiency, so it led to the selection of the other techniques like ANN. ANN is one of the machine learning reliable techniques because it is trained more than 1 time, whereas the traditional method is only trained once. This technique, used for many research fields, can solve the problem of data with complex patterns.

The benefits of the proposed method are high-grade at handling data that are multi-dimensional and multi-variety, and they can do this in dynamic or uncertain environments. However, it requires massive data sets to train the model, and these should be inclusive/unbiased, and of good quality. There can also be times where they must wait for new data to be generated.

All performance indicators of this model as influenced by controlling model parameters $\mathrm{S}, \mathrm{R}$ and $\mathrm{L}$ factors, are tabulated in Table 9. In Type 1 ( T1) scenario (including all factors), the F1-score regarding Macro average obtained from this model was 0.42. In Type 2 (T2) in which ' $S$ ' factor was not included, the F1-score significantly increased to 0.78 . When excluding ' $R$ ' and ' $S$ ' factors as in the case with Type 3 (T3), the F1-score further declined to 0.70 , suggesting the considerable significance of slope factor in the sense of model precision. When all 3 factors, i.e., S, R and L were excluded as in Type 4 (T4), the F1-score became 0.79 . According to their small magnitudes of weighted contribution (see Table 6), ' $S$ ', ' $R$ ' and ' $L$ ' factors have less significant contribution to the model. For instance, when comparing between (T1) and (T4) analysis, excluding ' $S$ ', ' $R$ ' and ' $L$ ' factors from the analysis leads to the increase in accuracy to 79 $\%$, whereas the analysis scenario with excluding ' $\mathrm{S}$ ' factor ( $\mathrm{T} 2)$ exhibited a slight decrease in accuracy to $78 \%$ compared to (T4) analysis. In addition, the analysis scenario excluding ' $S$ ' and ' $R$ ' factors (T3) showed a moderate decrease in accuracy to $70 \%$ compared to (T4) analysis. Consequently, on the basis of the finding of sensitivity analysis, it was concluded that ' $S$ ', ' $R$ ' and ' $L$ ' factors have no significant impact on the precision of the outcomes and for this study area. In addition, all statistical values of ANN were 0.79 in Type 4, not including ' $S$ ', ' $R$ ' and ' $L$ ' factors whereas, these values of Type 1(all causal factors) were 0.57. Therefore, it is clear that these causal factors are not necessary for this study area.

The decrease in neural nets performance is caused by several factors. First, the data used to create the model was unbalanced and discontinuous, due to the different sources and periods. Second, slope, flow accumulation and elevation values came from USGS/NASA SRTM DATA, which had different data collection methods, therefore these could lead to unsuitable results for Thailand. Rainfall intensities, from public organizations, were not accurate, because sometimes the collection used imprecise manual observations, therefore it may have errors. Land use labels were sometimes historical, collected manually, not updated and thus may have errors.

\section{Conclusions}

The main goal of this research is to develop a machine learning technique and then compare it with previous methods of identifying the flood susceptibility areas in this domain. ANN technique, produced by the causal factors, obtained a higher performance than traditional methodology. The main causal factors related to flood susceptibility map, were F, E and ST. Therefore, the proposed methodology for assessment of flood susceptibility areas could be applied to other regions to estimate the flood susceptibility areas, useful for impact assessment, rescue operations, agriculture, city planning and mitigation for handling and managing to reduce the outrage and blemish. Also, in case of a few dataset, evaluating techniques in machine learning capable of handling limited datasets such as cross validation can be adopted. However, the development of ANN prediction efficiency may include more relevant factors in future work as well as conducting more experiments with more advanced deep learning models.

\section{Acknowledgements}

We would like to thank the School of Science, King Mongkut's Institute of Technology Ladkrabang, for the Graduate Teaching/Research Assistant scholarship for Thanat Vajeethaveesin. We greatly acknowledge Geo-Informatics and Space Technology Development Agency (GISTDA), (USGS/NASA Shuttle Radar Topography Mission DATA, Shuttle Radar Topography Mission (SRTM), the Land Development Department (LDD), Thai Meteorological Department (TMD), and the National GeospatialIntelligence Agency (NGA) for providing the data set used in this study. 


\section{References}

[1] SMH Shah, Z Mustaffa, and KW Yusof. Disasters worldwide and floods in the Malaysian region: A brief review. Indian J. Sci. Tech. 2017; 10, 1-9.

[2] Ministry of Agriculture and Cooperatives. Report on impact of flood on farmers. Ministry of Agriculture and Cooperatives, 2011.

[3] D Komori, S Nakamura, M Kiguchi, A Nishijima, D Yamazaki, S Suzuki, A Kawasaki, K Oki and T Oki. Characteristics of the 2011 Chao Phraya River flood in central Thailand. Hydrolog. Res. Lett. 2012; 6, 41-6.

[4] N Thanvisitthpon. Impacts of repetitive floods and satisfaction with flood relief efforts: A case study of the flood-prone districts in Thailand's Ayutthaya province. Clim. Risk Manag. 2017; 18, 15-20.

[5] K Spachinger, W Dorner, R Metzka, K Serrhini and S Fuchs. Flood risk and flood hazard mapsvisualisation of hydrological risks. IOP Conf. Ser. Earth Environ. Sci. 2008; 4, 012043.

[6] NN Kourgialas and GP Karatzas. A flood risk decision making approach for Mediterranean tree crops using GIS; climate change effects and flood-tolerant species. Environ. Sci. Pol. 2016; 63, 132-42.

[7] SP Ozkan and C Tarhan. Detection of flood hazard in urban areas using GIS: Izmir case. Proc. Tech. 2016; 22, 373-81.

[8] N Kazakis, I Kougias and T Patsialis. Assessment of flood hazard areas at a regional scale using an index-based approach and analytical hierarchy process: Application in Rhodope- Evros region, Greece. Sci. Total Environ. 2015; 538, 555-63.

[9] D Oikonomidis, S Dimogiannia, N Kazakis and K Voudouris. A GIS/remote sensing- based methodology for groundwater potentiality assessment in Tirnavos area, Greece. J. Hydrolog. 2015; 525, 197-208.

[10] OF Althuwaynee, B Pradhan, HJ Park and JH Lee. A novel ensemble bivariate statistical evidential belief function with knowledge-based analytical hierarchy process and multivariate statistical logistic regression for landslide susceptibility mapping. Catena 2014; 114, 21-36.

[11] M Abdel-Basset, NA Nabeeh, HA El-Ghareeb and A Aboelfetouh. Utilising neutrosophic theory to solve transition difficulties of IoT-based enterprises. Enterprise Inform. Syst. 2020; 14, 1304-24.

[12] RA Deshmukh and R Hiremath. Analyzing the key performance indicators of advanced sustainable manufacturing system using AHP approach. In: P Pawar, B Ronge, R Balasubramaniam, A Vibhute, S Apte (Eds.). Techno-Societal 2018. Springer, Cham, Switzerland, 2020, p. 745-50.

[13] A Arabameri, K Rezaei, A Cerdà, C Conoscenti and Z Kalantari. A comparison of statistical methods and multi-criteria decision making to map flood hazard susceptibility in Northern Iran. Sci. Total Environ. 2019; 660, 443-58.

[14] T Wuest, D Weimer, C Irgens and KD Thoben. Machine learning in manufacturing: Advantages, challenges, and applications. Prod. Manuf. Res. 2016; 4, 23-45.

[15] XH Le, HV Ho, G Lee and S Jung. Application of long short-term memory (LSTM) neural network for flood forecasting. Water 2019; 11, 1387.

[16] Z Wang, C Lai, X Chen, B Yang, S Zhao and X Bai. Flood hazard risk assessment model based on random forest. J. Hydrolog. 2015; 527, 1130-41.

[17] TMD Melo and OC Pedrollo. Artificial neural networks for estimating soil water retention curve using fitted and measured data. Appl. Environ. Soil Sci. 2015; 2015, 535216.

[18] MS Tehrany, S Jones and F Shabani. Identifying the essential flood conditioning factors for flood prone area mapping using machine learning techniques. Catena 2019; 175, 174-92.

[19] MS Tehrany, B Pradhan and MN Jebur. Flood susceptibility mapping using a novel ensemble weights-of evidence and support vector machine models in GIS. J. Hydrolog. 2014; 512, 332-43.

[20] H Mojaddadi, B Pradhan, H Nampak, N Ahmad and AHB Ghazali. Ensemble machine-learningbased geospatial approach for flood risk assessment using multi-sensor remote-sensing data and GIS. Geomatics Nat. Hazards Risk 2017; 8, 1080-102.

[21] SH Mahmoud and TY Gan. Multi-criteria approach to develop flood susceptibility maps in arid regions of Middle East. J. Clean. Prod. 2018; 196, 216-29.

[22] MS Tehrany, L Kumar, MN Jebur and F Shabani. Evaluating the application of the statistical index method in flood susceptibility mapping and its comparison with frequency ratio and logistic regression methods. Geomatics Nat. Hazards Risk 2019; 10, 79-101.

[23] K Seejata, A Yodying, T Wongthadam, N Mahavik and S Tantanee. Assessment of flood hazard areas using analytical hierarchy process over the lower Yom Basin, Sukhothai Province. Proc. Eng. 2018; 212, 340-7. 
[24] L Stephens, DQ Fuller, N Boivin, T Rick, N Gauthier, AU Kay and et al. Archaeological assessment reveals Earth's early transformation through land use. Science 2019; 365, 897-902.

[25] R Monjo. Measure of rainfall time structure using the dimensionless n-index. Clim. Res. 2016; 67, 71-86.

[26] CJ Weir, I Butcher, V Assi, SC Lewis, GD Murray, P Langhorne and MC Brady. Dealing with missing standard deviation and mean values in meta-analysis of continuous outcomes: A systematic review. BMC Med. Res. Meth. 2018; 18, 25.

[27] Google Colab, Available at: https://colab.research.google.com/notebooks/welcome.ipynb, accessed May 2020.

[28] DP Kingma and $\mathrm{J}$ Ba. Adam: A method for stochastic optimization, Available at: https://arxiv.org/abs/1412.6980, accessed May 2020.

[29] F Pedregosa, G Varoquaux, A Gramfort, V Michel, B Thirion, O Grisel, M Blondel, P Prettenhofer, R Weiss, V Dubourg, J Vanderplas, A Passos, D Cournapeau, M Brucher, M Perrot and É Duchesnay. Scikit-learn: Machine learning in python. J. Mach. Learn. Res. 2011; 12, 2825-30.

[30] DR Jensen and DE Ramirez. Revision: Variance inflation in regression. Adv. Decis. Sci. 2013; 2013, 671204.

[31] JI Daoud. Multicolinearity and regression analysis. J. Phys. Conf. Ser. 2017; 949, 012009.

[32] R-squared definition, Available at: https://www.investopedia.com/terms/r/r-squared.asp, accessed July 2020. 